\title{
Downregulation of Transcription Factor Sp1 Suppresses Malignant Properties of A549 Human Lung Cancer Cell Line with Decreased B4-Galactosylation of Highly Branched $N$-Glycans
}

\author{
Kodai Muramoto, Riho Tange, Takayuki Ishii, Kana Miyauchi, and Takeshi Sato* \\ Laboratory of Glycobiology, Department of Bioengineering, Nagaoka University of Technology; Nagaoka, Niigata \\ 940-2188, Japan. \\ Received March 10, 2017; accepted May 9, 2017; advance publication released online May 20, 2017
}

\begin{abstract}
Dramatic changes in the glycan structures of cell surface proteins have been observed upon malignant transformation of cells as induced by the altered expression levels of glycosyltransferases. Such changes are closely associated with the malignant properties of cancer cells. Transcription factor Sp1 regulates the gene expression of various molecules including glycosyltransferases. Herein, we investigated whether or not Sp1downregulation affects to $\mathrm{N}$-glycosylation of glycoproteins and malignant properties of A549 human lung cancer cell line. We established a stable clone whose Sp1-expression level was reduced to $50 \%$ of a control clone by RNA interference. Lectin blotting revealed that the $\beta$ 4-galactosylation of highly branched $N$-glycans decreases mainly in cell adhesion molecule, E-cadherin. The analysis of underlying mechanism for decreased $\beta 4$-galactosylation of $N$-glycans showed that the gene expression level of $\beta 4$-galactosyltransferase $(\beta 4 G a l T)$ 1 decreases dramatically by downregulation of Sp1 without changes in those of $\beta 4 \mathrm{GalT} 2$ and $\mathrm{N}$-acetylglucosaminyltransferase $V$. Mutations in the Sp1-binding sites of the $\beta 4$ GalT1 gene promoter showed that the promoter activity decreases significantly, indicating that the gene expression is regulated by $\mathrm{Sp1}$. These results indicate that the $\beta 4$-galactosylation of highly branched $N$-glycans decreases by downregulation of $\mathrm{Sp} 1$ through the reduced expression of the $\beta 4$ GalT1 gene. Furthermore, the Sp1-downregulated cells showed the suppression of the anchorage-independent growth in soft agar and migratory activity when compared to the control cells. The present study demonstrates that downregulation of Sp1 suppresses the malignant properties of A549 cells through the decreased $\beta 4$-galactosylation of highly branched $N$-glycans.
\end{abstract}

Key words $\mathrm{Sp} 1 ; N$-glycan; $\beta 4$-galactosylation; $\beta 4$-galactosyltransferase 1 ; lung cancer; malignant property

In general, the carbohydrate structures of glycans attached to cell surface proteins change dramatically by malignant transformation. ${ }^{1,2)}$ The most prominent change is the increment of highly branched $N$-glycans containing the $\mathrm{Gal} \beta 1 \rightarrow 4 \mathrm{GlcNAc} \beta 1 \rightarrow 6 \mathrm{Man}$ group, which is synthesized by $N$-acetylglucosaminyltransferase (GlcNAcT) $\mathrm{V}$ and $\beta 4$ galactosyltransferase $(\beta 4 \mathrm{GalT})$. The increment of highly branched $N$-glycans is associated with malignant properties of cancer cells. ${ }^{3,4)}$ On the other hand, the GlcNAcT V-deficient mice, in which the amounts of highly branched $N$-glycans are reduced, showed that the growth and metastasis of mammary tumor induced by polyoma virus middle $\mathrm{T}$ oncogene are suppressed. ${ }^{5)}$ Therefore, the biosynthetic pathway of highly branched $N$-glycans is considered to be important for expressing the malignant properties of cancer cells.

The gene expression levels of several glycosyltransferases including GlcNAcT IVa, GlcNAcT V, $\beta 4$ GalT1, $\beta 4$ GalT5, fucosyltransferase (FUT) I, FUT II, and $\alpha$-2,6-sialyltransferase I have been shown to increase in cancer cells, ${ }^{6-12)}$ and the changes in glycosylation induced by the altered expression levels of the glycosyltransferase genes are closely associated with the malignant properties of cancer cells. The GC-rich promoter, which lacks the TATA and CCAAT boxes, appears to be characteristic of mammalian glycosyltransferase genes, and the consensus binding sites for transcription factor $\mathrm{Sp} 1$ are found in the promoter regions of the glycosyltransferase genes. ${ }^{13)} \mathrm{Sp} 1$ belongs to the Sp transcription factor family containing zinc finger DNA binding domains, which bind to the $\mathrm{GC}$ box in the promoter and enhancer regions, and is involved in the regulation of many housekeeping genes. ${ }^{14)}$ Since the expression of $\mathrm{Spl}$ has been reported to upregulate in various cancer cells such as lung, breast, gastric, and pancreatic cancer cells, ${ }^{15)}$ the expression levels of some glycosyltransferase genes are considered to increase in cancer cells due to upregulation of Sp1-expression.

Our previous studies demonstrated that the malignant properties of cancer cells are suppressed by regulation of the expression levels of the $\beta 4 \mathrm{GalT}$ genes, ${ }^{16,17)}$ indicating that the changes of cell surface glycosylation contribute to the suppression of malignant properties of cancer cells. Therefore, if Spl-expression is downregulated by RNA interference (RNAi), not only the expression of cancer-related molecules but also glycosylation patterns can be changed in accordance with the altered gene expression of glycosyltransferases, which may lead to the suppression of malignant properties of cancer cells. In the present study, we established a stable clone whose Spl-expression level was reduced by introducing small interfering RNA (siRNA) expression vector into A549 human lung cancer cell line, which contains large amounts of $\mathrm{Sp} 1,{ }^{18)}$ investigated the cell surface protein glycosylation and malignant properties of the cells, and identified the glycosyltransferase gene responsible for the altered glycosylation by downregulation of Sp1.

\section{MATERIALS AND METHODS}

Cell Line and Reagents A549 human lung cancer cell line was cultured in Dulbecco's modified Eagle's medium 
(DMEM) containing 10\% fetal calf serum (FCS), 50 units $/ \mathrm{mL}$ penicillin and $50 \mu \mathrm{g} / \mathrm{mL}$ streptomycin. Rabbit anti-human $\beta$-actin, anti-human Sp1, anti-human E-cadherin, and antihuman lysosome-associated membrane protein-1 (LAMP-1) antibodies were obtained from Santa Cruz Biotechnology (Santa Cruz, CA, U.S.A.). Horseradish peroxidase-conjugated concanavalin A (Con A), Ricinus communis agglutinin-I (RCA-I), leuko-agglutinating phytohemagglutinin (L-PHA), and L-PHA-agarose were purchased from Seikagaku Kogyo (Tokyo). Mithramycin A was obtained from Sigma-Aldrich (St. Louis, MO, U.S.A.).

Plasmid Construction For downregulation of $\mathrm{Sp} 1$ by RNAi, the target nucleotide sequences were selected from the human Sp1 gene (GenBank ${ }^{\mathrm{TM}}$ accession number: NM_138473) by siRNA Target Finder (Ambion, Austin, TX, U.S.A.). The uniqueness of each target sequence to the Sp1 mRNA was verified by BLAST analysis. The oligonucleotides, TSSP1 (5'GAT CCT GGG GGC AAT GGT AAT GGT TTC AAG AGA ACC ATT ACC ATT GCC CCC ATT A-3') and TSSP2 (5'-AGC TTA ATG GGG GCA ATG GTA ATG GTT CTC TTG AAA CCA TTACCATTGCCCCCAG-3'), were designed and annealed for generating the double-stranded DNA fragment. The DNA fragment was ligated into the BamHI-HindIII sites of the pSilencer4.1-hygro vector (Ambion), to generate pSilencer/ siSp1. As a control, pSilencer/Negative control vector (Ambion) was used.

Since the promoter region of the human $\beta 4 \mathrm{GalT} 1$ gene was identified, ${ }^{9)}$ the promoter region $(-500 /-1$ relative to the initiation codon) was synthesized, and ligated into pGL3-Basic vector (Promega, Madison, WI, U.S.A.), to generate pGLGT1 $(-500 /-1)$. In order to generate three plasmids, pGLGT1mSP1, pGL-GT1mSP2, and pGL-GT1mSP3, the mutations in the Spl-binding sites were introduced using pGL-GT1 $(-500 /-1)$ and KOD-Plus-Mutagenesis Kit (TOYOBO, Osaka, Japan) according to the manufacturer's instructions. The wildtype sequences of the Spl-binding sites, GCCCCGCCCC, at nucleotide positions $-236 /-227$ and $-213 /-204$ were replaced with GCCCCG underlined. pGL-GT1mSP1 and pGL-GT1mSP2 contain the mutation in the Spl-binding sites $-236 /-227$ and $-213 /-204$, respectively. pGL-GT1mSP3 contains the mutations in both Spl-binding sites. The correct sequences of plasmids with mutations were confirmed by nucleotide sequencing.

Transfection A549 cells were transfected with pSilencer/ siSp1 and pSilencer/Negative control vector to establish the Spl-downregulated cell clones and the control cell clone, respectively, as described previously. ${ }^{16,17)}$ After being cultured for $72 \mathrm{~h}$, the plasmid-transfected cells were selected with DMEM containing 10\% FCS and hygromycin B $(500 \mu \mathrm{g} / \mathrm{mL})$ for two weeks.

Western Blotting The control and Spl-downregulated cells were homogenized, and then subjected to acetone precipitation as described previously. ${ }^{19)}$ The defatted samples referred to as membrane glycoprotein samples were analyzed by Western blotting. Western blotting with Con A, RCA-I, L-PHA, or the antibody against Sp1, E-cadherin, or LAMP-1 was conducted as described previously. ${ }^{20,21)}$ In the case of incubation with RCA-I and L-PHA, the filters were initially treated with $25 \mathrm{~mm}$ sulfuric acid at $80^{\circ} \mathrm{C}$ for $1 \mathrm{~h}$. Lectin precipitation using L-PHA-agarose was performed as the method described previously. ${ }^{22)}$ The intensity of Spl protein bands was determined, and the ratios between those of control and Spl-downregulated cells were calculated as described previously. ${ }^{16,23)}$

Quantitative Real-Time RT-PCR Analysis Quantitative real-time RT-PCR analysis was conducted as the method described previously. ${ }^{24)}$ The oligonucleotide primers specific to each gene were as follows: Sp1, F: 5'-GCC TCC AGA CCA TTA ACC TCA G-3', R: 5'-TCA TGT ATT CCA TCA CCA CCA G-3'; $\beta 4$ GalT1, F: 5'-CGT TGC AAT GGA TAA GTT TGG ATT C-3', R: 5'-CAGCAT TTG GGC GAG ATA TAGACA-3'; $\beta 4$ GalT2, F: 5'-ACG GCG TCT ATG TCA TCA ACC A-3', R: 5'-ACC AGG TCC ACA TCGCTGAAG-3'; GlcNAcT V, F: 5'-GAGCAGATC CTG GAC CTC AG-3', R: 5'-GCT GTC ATG ACT CCA GCG TA3'; glyceraldehyde 3-phosphate dehydrogenase (G3PDH), F: 5'GCA CCG TCA AGGCTG AGA AC-3'， R: 5'-TGG TGA AGA CGC CAG TGG A-3'.

Luciferase Assay The promoter activities of the reporter plasmids were determined by luciferase assay as described previously. ${ }^{13,23)}$ Mithramycin A $(0.1 \mu \mathrm{M})$ was added to A549 cells $1 \mathrm{~h}$ after transfection with pGL-GT1 $(-500 /-1)$ as described previously. ${ }^{13)}$

Cell Proliferation Assay Cells were seeded into 96-well plates at a density $1 \times 10^{3}$ per well, and incubated for one to seven days. Growth rates of the control and Sp1-downregulated cells were examined using Celltiter 96 aqueous one solution cell proliferation assay (Promega) according to the manufacture's instructions. The absorbance of each well at $490 \mathrm{~nm}$ was measured using a microtiter plate reader.

Anchorage-Independent Cell Growth Assay Anchorageindependent cell growth assay was carried out as described previously. ${ }^{25,26)}$ In 12-well tissue culture plates, $0.6 \%$ agarose was placed as bottom agarose, and then $2 \times 10^{3}$ cells suspended in $0.3 \%$ agarose with DMEM containing $10 \%$ FCS were placed on the top of the bottom agarose. The plates were incubated for three weeks. The colony numbers $(>100 \mu \mathrm{m}$ in diameter) and colony sizes in five fields were measured under a microscope.

Wound Healing Assay Wound healing assay was performed as described previously. ${ }^{22)}$ In brief, cells were seeded into 24-well tissue culture plate and grown to confluence. The cell monolayers were scratched with $200 \mu \mathrm{L}$ yellow plastic tip, and then extensively washed with serum-free DMEM. The cells were incubated in DMEM containing 2\% FCS and $100 \mathrm{ng} / \mathrm{mL}$ epidermal growth factor for the indicated time periods. Migration of the control and Sp1-downregulated cells into wound area was photographed with a microscope, and then cell migration distances were chronologically measured with a micrometer. The relative wound widths were expressed by taking the distance at the initial time as 1.0.

Statistical Analysis A significant difference was assessed by Student's $t$-test.

\section{RESULTS}

Establishment of Sp1-Downregulated Cell Clone For downregulation of $\mathrm{Sp1}$, the expression plasmid for siRNA against Sp1, pSilencer/siSp1, was transfected into A549 cells, and stable clones were obtained after selection with hygromycin B. One of the clones showed that the expression of the Sp1 gene decreases by $30 \%$ as compared to that of the control cell clone (Fig. 1A). Immunoblot analysis using an anti-Spl anti- 
body showed that the expression of Spl decreases to approximately $50 \%$ in this clone when compared with the control cell clone (Fig. 1B), showing the highest level of Sp1-downregulation among the stable clones established. Since Sp1 is essential for various cellular functions including cell proliferation, ${ }^{15}$ ) the reason why the Sp1-downregulated cells with the expression level of Sp1 lower than $50 \%$ could not be obtained may be due to the dysfunction of cell proliferation. Therefore, in this study, we used the clone with the expression level of Sp1 reduced by $50 \%$ as the Sp1-downregulated cells.

Decreased $\boldsymbol{\beta} 4$-Galactosylation of $\boldsymbol{N}$-Glycans on ECadherin by Sp1-Downregulation Coomassie Brilliant Blue $(\mathrm{CBB})$ staining showed that the membrane glycoprotein samples from the control and Sp1-downregulated cells appear similar protein components (lanes 1 and 2 of Fig. 2-CBB). To analyze whether or not the cell surface $N$-glycosylation changes in A549 cells by downregulation of Sp1, lectin blotting was conducted using Con A, RCA-I, and L-PHA. No significant change in the binding of Con $\mathrm{A}$, which interacts mainly with high mannose-type $N$-glycans, ${ }^{27)}$ was detected between the control and Spl-downregulated cells (lanes 1 and 2 of Fig. 2-Con A), suggesting that the amounts of $N$-glycan subgroup are not changed by downregulation of Sp1. The filters were initially subjected to sulfuric acid treatment to remove sialic acid linked to galactose residues, and then incubated with RCA-I, which binds to glycans terminating with the $\mathrm{Gal} \beta 1 \rightarrow 4$ GlcNAc group. ${ }^{28)}$ A significant decrease in the lectin binding was observed for 76-86, 90, 94, 120, 145 and $160 \mathrm{kDa}$ of protein bands in the Sp1-downregulated cells as compared

A

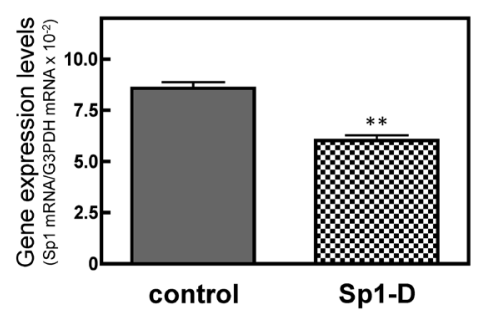

Fig. 1. The Expression Level of Spl in the Sp1-Downregulated Cells

(A) The expression levels of the Sp1 transcript in the control and Spl-downregulated cells (Sp1-D) relative to those of the G3PDH transcript. Data show the means \pm S.D. $(n=3)$. **indicates $p<0.01$ against control. (B) Immunoblot showing expression of Sp1 protein in the control and Sp1-downregulated cells (Sp1-D). The ratio of amounts of Sp1 against $\beta$-actin between the control and Spl-downregulated cells is shown at the bottom of the Sp1-blot. with the control cells (lanes 1 and 2 of Fig. 2-RCA-I). Upon incubation with L-PHA, which recognizes specifically highly branched $N$-glycans with the $\mathrm{Gal} \beta 1 \rightarrow 4 \mathrm{GlcNAc} \beta 1 \rightarrow 6(\mathrm{Gal} \beta 1 \rightarrow$ $4 \mathrm{GlcNAc} \beta 1 \rightarrow 2$ )Man branch, ${ }^{29)} 76-86,90,94$ and $120 \mathrm{kDa}$ of protein bands reacted weakly to the lectin in the Sp1-downregulated cells as compared with the control cells (lanes 1 and 2 of Fig. 2-L-PHA). The L-PHA-reactive protein bands were considered to correspond, most probably, to those bound to RCA-I as shown in Fig. 2-RCA-I. The carbohydrate-binding specificities of each lectin were confirmed by the methods as described previously. ${ }^{17,20)}$

When the filters were incubated with the antibodies, the 90 and $94 \mathrm{kDa}$ of protein bands reacted with anti-LAMP-1 antibody, and the $120 \mathrm{kDa}$ of protein band reacted strongly with anti-E-cadherin antibody (lanes 1 and 2 of Fig. 2-LAMP-1 and E-cadherin). LAMP-1 is a membrane glycoprotein that is predominantly expressed in lysosome. ${ }^{30)}$ In this study, we focused on the $120 \mathrm{kDa}$ of protein band, presumably E-cadherin, which is the well-characterized cell adhesion molecule. ${ }^{31)}$ In order to identify the L-PHA-reactive $120 \mathrm{kDa}$ of protein band, lectin precipitation using L-PHA followed by immunoblot analysis with anti-E-cadherin antibody was performed. The results showed that the L-PHA-reactive $120 \mathrm{kDa}$ of protein band is identified as E-cadherin (Fig. 3). As shown in Fig. 2-E-cadherin, the expression of E-cadherin unchanged by downregulation of Sp1. On the other hand, the expression of LAMP-1 appeared to increase slightly in the Sp1-downregulated cells as compared with the control cells (Fig. 2-LAMP-1). Taken together, these results suggest that the $\beta 4$-galactosylation of highly branched $N$-glycans on E-cadherin and LAMP-1 decreases by downregulation of Sp1.

Reduced Expression of $\beta 4$ GalT1 Gene by Sp1-Downregulation The $\mathrm{Gal} \beta 1 \rightarrow 4 \mathrm{GlcNAc} \beta 1 \rightarrow 6 \mathrm{Man}$ group in the highly branched $N$-glycans is synthesized by GlcNAcT V and $\beta 4$ GalTs. Although there are seven $\beta 4 \mathrm{GalTs}$ in mammalian cells, $\beta 4$ GalT1 and $\beta 4$ GalT2 are involved in the $\beta 4$ galactosylation of $N$-glycans. ${ }^{32)}$ To elucidate the background of the altered $\mathrm{N}$-glycosylation by downregulation of $\mathrm{Sp1}$, the expression levels of the $\beta 4 \mathrm{GalT} 1, \beta 4 \mathrm{GalT} 2$, and GlcNAcT $\mathrm{V}$ genes were analyzed by quantitative real-time RT-PCR. The results showed that the expression level of the $\beta 4 \mathrm{GalT} 1$ gene in the Spl-downregulated cells decreases to $45 \%$ of the control cells (Fig. 4- $\beta 4$ GalT1). However, the expression levels of the $\beta 4 \mathrm{GalT} 2$ and GlcNAcT $\mathrm{V}$ genes unchanged between the control and Sp1-downregulated cells (Fig. 4- $\beta 4$ GalT2 and GlcNAcT V). These results strongly suggest that the decreased

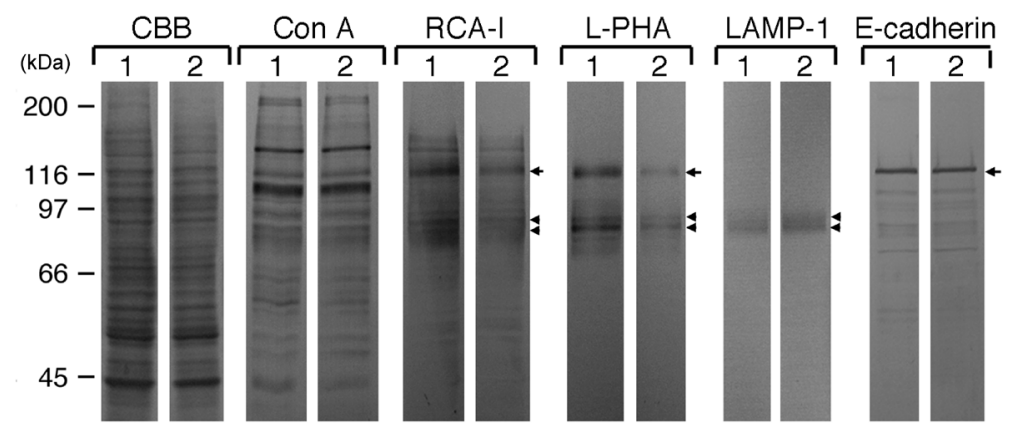

Fig. 2. Western Blotting of Membrane Glycoproteins from the Control and Sp1-Downregulated Cells

The filters were incubated with CBB, Con A, RCA-I, L-PHA, anti-LAMP-1 antibody, and anti-E-cadherin antibody. Lanes 1 and 2 indicate the samples from the control and Spl-downregulated cells, respectively. The arrow and arrowhead indicate the protein bands, which are reacted with anti-E-cadherin and anti-LAMP-1 antibodies, respectively. 


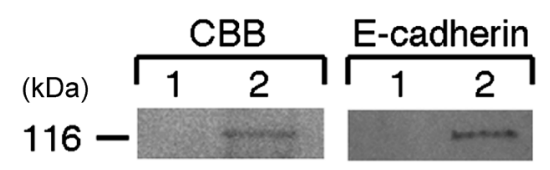

Fig. 3. Identification of the L-PHA-Reactive $120 \mathrm{kDa}$ of Protein Band in A549 Cells

A549 cell lysates were incubated with agarose (lane 1) or L-PHA-agarose (lane 2) followed by immunoblot analysis with anti-E-cadherin antibody.

$\beta 4$-galactosylation of highly branched $N$-glycans in A549 cells by downregulation of $\mathrm{Sp} 1$ is brought about by the reduced expression of the $\beta 4 \mathrm{GalT} 1$ gene.

Mithramycin A is well-known inhibitor for binding of Sp1 to its binding site in DNA. ${ }^{33,34)}$ By the treatment of A549 cells with mithramycin $\mathrm{A}$, the expression of the $\beta 4 \mathrm{GalT} 1$ gene decreased significantly (Fig. 5A), suggesting that the expression of the $\beta 4 \mathrm{GalT} 1$ gene is regulated by $\mathrm{Sp} 1$. To confirm this further, the promoter activity of the $\beta 4 \mathrm{GalT} 1$ gene was analyzed by luciferase assay. Two Spl-binding sites were predicted at nucleotide positions $-236 /-227$ (score: 94.5) and $-213 /-204$ (score: 94.5 ) relative to the initiation codon in the $\beta 4 \mathrm{GalT1}$ gene promoter by TFSEARCH program version 1.3 (http://www.cbrc.jp/research/db/TFSEARCH.html). We generated three constructs pGL-GT1mSP1, pGL-GT1mSP2, and pGL-GT1mSP3, in which the Sp1-binding sites were mutated (Fig. 5B). Our previous study clearly demonstrated that the similar mutation in the Sp1-binding site reduces the Sp1-binding to the promoter region, and leads to the decreased promoter activity of the human $\beta 4 \mathrm{GalT} 5$ gene. ${ }^{13)}$ Upon transfection of these constructs into A549 cells, the luciferase activities decreased drastically when compared with the cells transfected with pGL-GT1 (-500/-1) (Fig. 5B). These results suggest that the Spl-binding sites are critical and Spl plays pivotal roles in the promoter activity of the $\beta 4 \mathrm{GalT} 1$ gene.

Suppression of Malignant Properties by Sp1-Downregulation The growth rate of the Sp1-downregulated cells was examined by cell proliferation assay. The results showed that in a growth phase, the growth rate of the Spl-downregulated cells decreases by $17-31 \%$ compared to the control cells (Fig. 6), indicating that downregulation of Sp1 suppresses the cell growth. Generally, anchorage-independent cell growth in soft agar is correlated to tumorigenic potentials of cancer cells. Anchorage-independent cell growth assays showed that the average sizes of colonies formed by the control and Sp1downregulated cells were $104.6+5.7 \mu \mathrm{m}$ and $73.7+1.9 \mu \mathrm{m}$, respectively (Fig. 7A). In addition, the numbers of colonies over
$100 \mu \mathrm{m}$ in diameter formed by the control cells were $38 \pm 6.2$ whereas those formed by the Spl-downregulated cells were $10 \pm 0.8$ (Fig. 7B). These results indicate that the anchorageindependent growth of A549 cells is reduced significantly by downregulation of Sp1. Dynamic cell movement is one of the characteristic features of cancer cells, and is related to metastasis. Next, the migratory activity of the Sp1-downregulated cells was examined by wound healing assay. The results showed that after $24 \mathrm{~h}$ incubation, more than $80 \%$ of the wound area is filled in the control cells, but about $55 \%$ of the area is filled in the Sp1-downregulated cells (Fig. 8), indicating that the migratory activity decreases by downregulation of Sp1. Taken together, these results demonstrate that the malignant properties of A549 cells decrease by downregulation of Spl.

\section{DISCUSSION}

The highly branched $N$-glycans have been shown to be involved in the malignant properties of cancer cells. ${ }^{3-5)}$ In the present study, we established the Spl-downregulated cells without apparent changes in protein components from human lung cancer cell line, and clearly demonstrated that by downregulation of $\mathrm{Sp} 1$ the $\beta 4$-galactosylation of highly branched $N$-glycans on E-cadherin decreases (Fig. 2), and the malignant properties are suppressed (Figs. 6-8). Furthermore, we identified the $\beta 4 \mathrm{GalT1}$ gene as the responsible gene for the decreased $\beta 4$-galactosylation of $N$-glycans by Sp1-downregulation (Fig. 4). As human $\beta 4 \mathrm{GalT1}$ has been shown to be involved in the $\beta 4$-galactosylation of highly branched $N$-glycans, ${ }^{35,36)}$ the binding of RCA-I and L-PHA, both of which interact with the $\beta 4$-galactosylated $N$-glycans, ${ }^{28,29)}$ decreased significantly in the Sp1-downregulated cells as the results of the reduced expression of the $\beta 4$ GalT1 gene (Figs. 2, 4). These results indicate that the biosynthesis of highly branched $N$-glycans is inhibited by downregulation of Spl. Since the highly branched $N$-glycans have been shown to be important for malignant properties of cancer cells, ${ }^{3-5)}$ the inhibition of the biosynthesis of highly branched $N$-glycans by Sp1-downregulation could partly contribute to the suppression of malignant properties of A549 cells with changes in the gene expression of cancerrelated molecules. Moreover, sialylated glycans have been shown to be associated with malignant properties of cancer cells. ${ }^{37)}$ Since the terminal galactose residues of glycans are often sialylated, ${ }^{37)}$ the decreased $\beta 4$-galactosylation of $N$-glycans by Sp1-downregulation is considered to bring about the
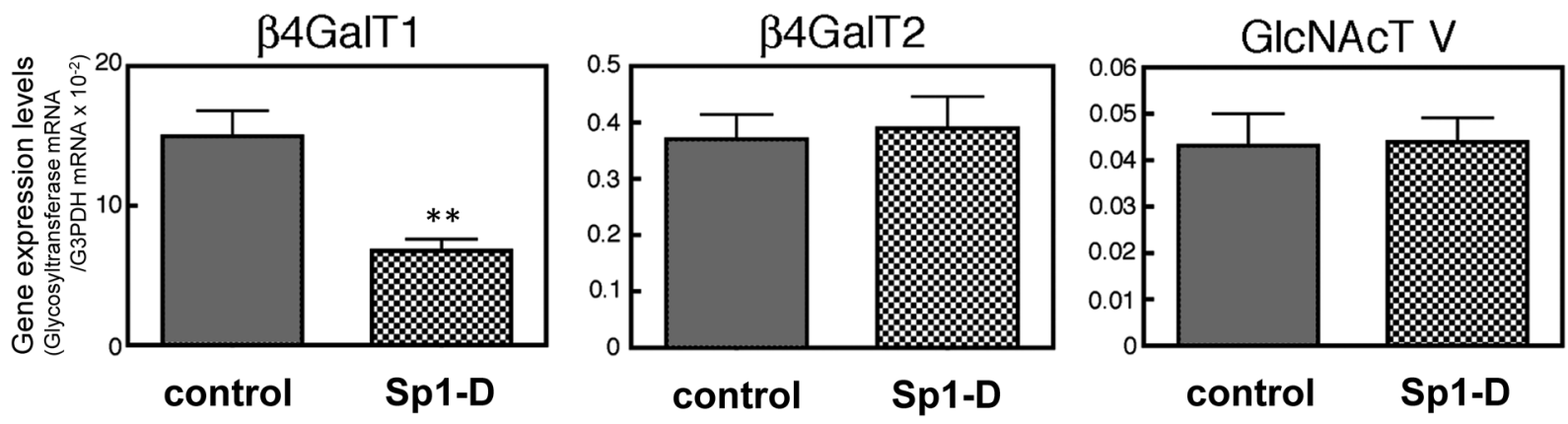

Fig. 4. Comparison of the Expression Levels of the $\beta 4 \mathrm{GalT1}, \beta 4 \mathrm{GalT} 2$, and GlcNAcT V Genes between the Control and Sp1-Downregulated Cells (Sp1-D)

Data show the means \pm S.D. $(n=3)$. **indicates $p<0.01$ against control 
A

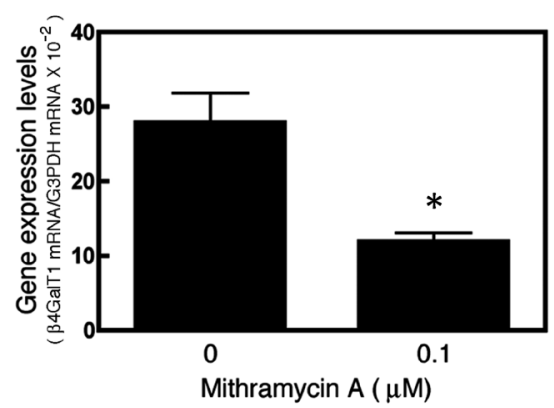

B

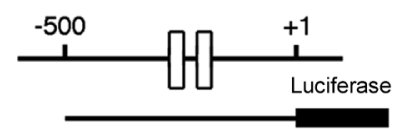

pGL-GT1 (-500/-1)

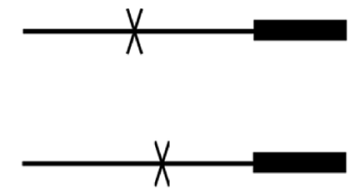

pGL-GT1mSP1
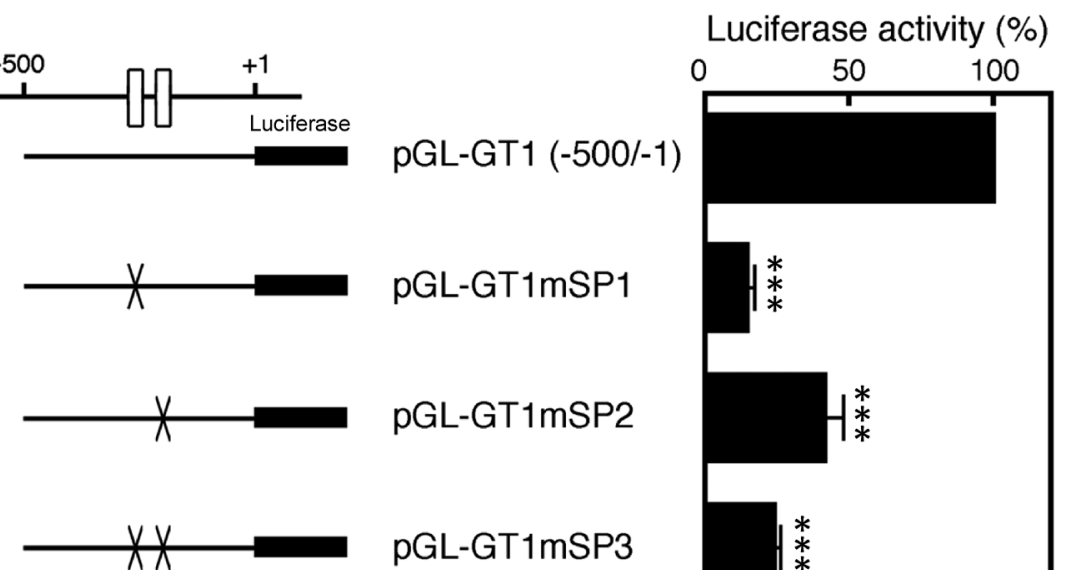

pGL-GT1mSP2

pGL-GT1mSP3

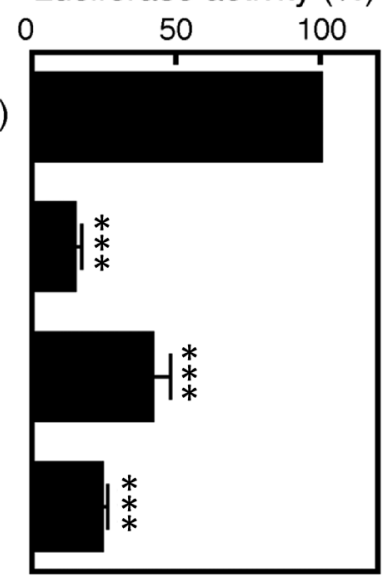

Fig. 5. Regulatory Mechanism of the $\beta 4 \mathrm{GalT} 1$ Gene by Sp1

(A) Comparison of the expression levels of the $\beta 4 \mathrm{GalT} 1$ gene between mithramycin A-treated and -untreated A549 cells. Data show the means \pm S.D. $(n=3)$. $*$ indicates $p<0.05$ against control. (B) A549 cells were transiently transfected with pGL-GT1 (-500/-1), pGL-GT1mSP1, pGL-GT1mSP2, or pGL-GT1mSP3. The promoter activity of pGL-GT1 $(-500 /-1)$ was taken as $100 \%$. Data show the means \pm S.D. $(n=3)$. ***indicates $p<0.001$ against pGL-GT1 $(-500 /-1)$.

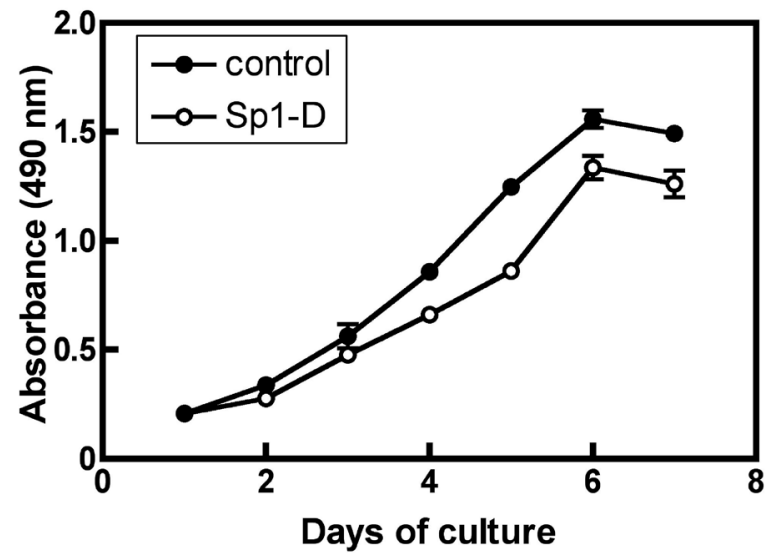

Fig. 6. Effect of Sp1-Downregulation on Proliferation of A549 Cells Closed and open circles indicate the control and Sp1-downregulated cells (Sp1-D), respectively. Data show the means \pm S.D. $(n=3)$.

decreased sialylation of $N$-glycans partially, which may also lead to the suppression of malignant properties of A549 cells.

The expression of $\beta 4 \mathrm{GalT} 1$ has been shown to increase in highly metastatic human lung cancer cells, PGBE1, when compared with its less metastatic lung cancer cells, PGLH7. ${ }^{9)}$ The migratory activity of PGBE1 was higher than that of PGLH7, and the invasive potential of PGBE1 decreased by reducing the expression of the $\beta 4 \mathrm{GalT} 1$ gene with RNAi. ${ }^{9}$ Therefore, the $\beta 4$-galactosylated $N$-glycans to be synthesized by $\beta 4 \mathrm{GalT} 1$ could be involved in the malignant properties of lung cancer cells. In fact, we found that by reducing the expression of the $\beta 4$ GalT1 gene with RNAi, the anchorage independent growth of A549 cells is suppressed similar to the Spl-downregulated cells (unpublished data). The decreased $\beta 4$-galactosylation of highly branched $N$-glycans by $\mathrm{Spl}$-downregulation was mainly observed for E-cadherin (Figs. 2, 3). As the changes in $\mathrm{N}$-glycosylation of E-cadherin have been shown to suppress the malignant properties of cancer cells by modulating the cell adhesion, ${ }^{38)}$ the changes in $N$-glycosylation of E-cadherin could contribute to the suppression of the malignant properties of A549 cells. However, the decreased $\beta 4$-galactosylation was also observed for LAMP-1, which was tentatively identified by immunoblot analysis (Fig. 2). Since LAMP-1 containing oversialylated glycans has been shown to enhance lysosomal exocytosis, which promotes the migration and invasion of human sarcoma cells, ${ }^{39)}$ the changes in $N$-glycans of LAMP-1 could be involved in the suppression of the malignant properties. Although LAMP-1 is a lysosomal membrane glycoprotein, ${ }^{30}$ its cell surface expression is detected in small amounts. ${ }^{40}$ Therefore, the changes in $N$-glycosylation of LAMP-1 could contribute to the suppression of the malignant properties, too. The mechanism of the reduced malignant properties by downregulation of $\mathrm{Sp} 1$ is currently unknown. Analysis of the signal transduction and expression of cancer-related molecules in the Spl-downregulated cells will provide the further understanding of the molecular mechanism of the reduced malignant properties of A549 cells.

In mouse somatic tissues, the expression of the $\beta 4 \mathrm{GalT} 1$ 
A

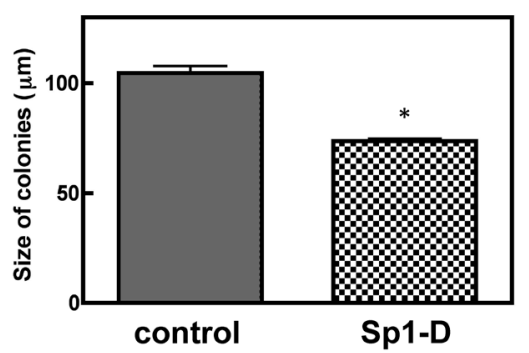

B

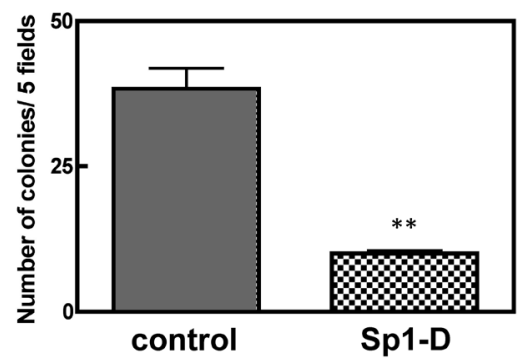

Fig. 7. Effect of Sp1-Downregulation on Anchorage-Independent Growth of A549 Cells

(A) Sizes of colonies formed by the control and Sp1-downregulated cells. Data show the means \pm S.D. $(n=3)$. * indicates $p<0.05$ against control. (B) Numbers of colonies over $100 \mu \mathrm{m}$ in diameter formed by the control and Sp1-downregulated cells. Data show the means \pm S.D. $(n=3)$. $* *$ indicates $p<0.01$ against control.

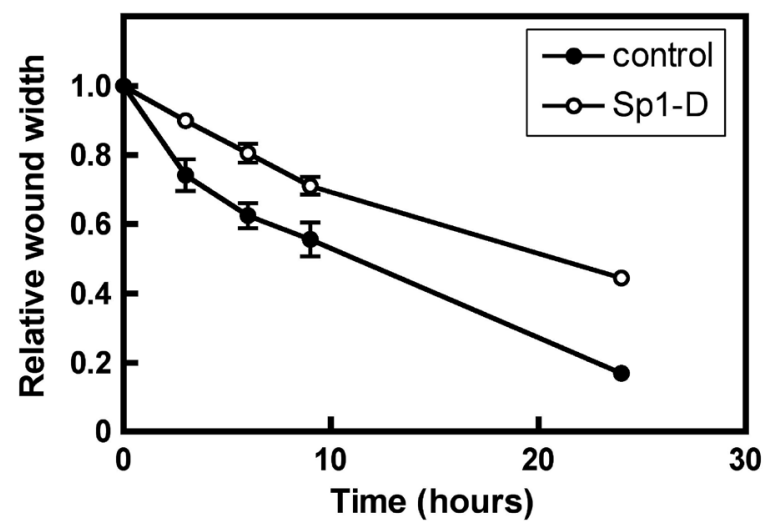

Fig. 8. Effect of Sp1-Downregulation on Migratory Activity of A549 Cells

Closed and open circles indicate the control and Sp1-downregulated cells (Sp1-D), respectively. Data show the means \pm S.D. $(n=3)$.

gene was regulated by a promoter having multiple Spl-binding sites. ${ }^{41,42)}$ Our results showed that the expression of the $\beta 4$ GalT1 gene decreases by the treatment with mithramycin A (Fig. 5A), which is an inhibitor for Spl-binding, ${ }^{33,34)}$ and the promoter activity decreases dramatically when the mutations were introduced in the Spl-binding sites of the human $\beta 4 \mathrm{GalT1}$ promoter region (Fig. 5B). These results indicate that $\mathrm{Sp} 1$ plays pivotal roles in the expression of the $\beta 4 \mathrm{GalT} 1$ gene. However, other transcription factors could also involve in the expression of the $\beta 4 \mathrm{GalT} 1$ gene since significant promoter activity was still detected though the mutations were introduced in both Sp1-binding sites (Fig. 5B). For instance, E1AF has been reported to activate the $\beta 4 \mathrm{GalT} 1$ gene promoter, ${ }^{9)}$ which supports this possibility. On the other hand, the expression levels of the $\beta 4 \mathrm{GalT} 2$ and GlcNAcT $\mathrm{V}$ genes unchanged by downregulation of Spl. Since the expression of the human $\beta 4 \mathrm{GalT} 2$ and GlcNAcT $\mathrm{V}$ genes has been shown to be regulated by p53 and Ets-1, respectively, ${ }^{43,44)}$ downregulation of Spl could not affect to the expression levels of these genes.

This is the report, for the first time, showing that downregulation of Sp1 suppresses malignant properties of human lung cancer cell line in part due to the decreased $\beta 4$-galactosylation of highly branched $N$-glycans. The reduced expression of the Spl gene in human fibrosarcoma cells by using Sp1 ribozyme antisense resulted in the suppression of tumorigenic potential with the decreased gene expression of vascular endothelial growth factor, which is one of the key molecules for tumor angiogenesis. ${ }^{45)}$ By regulating the expression of transcription factors in cancer cells, the glycosyltransferases and cancerrelated molecules can be regulated simultaneously, which may lead to the suppression of the malignant properties of cancer cells synergistically and effectively.

Acknowledgments This work was supported by Japan Society for the Promotion of Science KAKENHI Grant Numbers 19590062 and 23590070 from the Ministry of Education, Culture, Sports, Science and Technology of Japan to TS, and by Institutional Grants from Nagaoka University of Technology.

Conflict of Interest The authors declare no conflict of interest.

\section{REFERENCES}

1) Ohtsubo K, Marth JD. Glycosylation in cellular mechanisms of health and disease. Cell, 126, 855-867 (2006).

2) Lau KS, Dennis JW. N-Glycans in cancer progression. Glycobiology, 18, 750-760 (2008)

3) Demetriou M, Nabi IR, Coppolino M, Dedhar S, Dennis JW. Reduced contact-inhibition and substratum adhesion in epithelial cells expressing GlcNAc-transferase V. J. Cell Biol., 130, 383-392 (1995).

4) Asada M, Furukawa $K$, Segawa $K$, Endo T, Kobata A. Increased expression of highly branched $\mathrm{N}$-glycans at cell surface is correlated with the malignant phenotypes of mouse tumor cells. Cancer Res., 57, 1073-1080 (1997).

5) Granovsky M, Fata J, Pawling J, Muller WJ, Khokha R, Dennis JW. Suppression of tumor growth and metastasis in Mgat5-deficient mice. Nat. Med., 6, 306-312 (2000).

6) Takamatsu S, Oguri S, Minowa MT, Yoshida A, Nakamura K, Takeuchi M, Kobata A. Unusually high expression of $N$-acetylglucosaminyltransferase-IVa in human choriocarcinoma cell lines: a possible enzymatic basis of the formation of abnormal biantennary sugar chain. Cancer Res., 59, 3949-3953 (1999).

7) Yamashita K, Tachibana Y, Ohkura T, Kobata A. Enzymatic basis for the structural changes of asparagine-linked sugar chains of membrane glycoproteins of baby hamster kidney cells induced by polyoma transformation. J. Biol. Chem., 260, 3963-3969 (1985).

8) Arango J, Pierce M. Comparison of $\mathrm{N}$-acetylglucosaminyltransferase $\mathrm{V}$ activities in Rous sarcoma-transformed baby hamster kidney (RS-BHK) and BHK cells. J. Cell. Biochem., 37, 225-231 (1988).

9) Zhu X, Jiang J, Shen H, Wang H, Zong H, Li Z, Yang Y, Niu Z, Liu $\mathrm{W}$, Chen $\mathrm{X}, \mathrm{Hu} \mathrm{Y}, \mathrm{Gu}$ J. Elevated $\beta$-1,4-galactosyltransferase I in highly metastatic human lung cancer cells: identification of E1AF as important transcription activator. J. Biol. Chem., 280, 12503-12516 (2005)

10) Shirane K, Sato T, Segawa K, Furukawa K. Involvement of $\beta$-1,4- 
galactosyltransferase $\mathrm{V}$ in malignant transformation-associated changes in glycosylation. Biochem. Biophys. Res. Commun., 265 434-438 (1999).

11) Fukushima $\mathrm{K}$, Hara-Kuge $\mathrm{S}$, Seko A, Ikehara $Y$, Yamashita $\mathrm{K}$ Elevation of $\alpha 2 \rightarrow 6$ sialyltransferase and $\alpha 1 \rightarrow 2$ fucosyltransferase activities in human choriocarcinoma. Cancer Res., 58, 4301-4306 (1998).

12) Dall'Olio F, Chiricolo M, Ceccarelli C, Minni F, Marrano D, Santini D. $\beta$-Galactoside $\alpha 2,6$ sialyltransferase in human colon cancer: contribution of multiple transcripts to regulation of enzyme activity and reactivity with Sambucus nigra agglutinin. Int. J. Cancer, 88, 58-65 (2000)

13) Sato T, Furukawa K. Transcriptional regulation of the human $\beta$-1,4galactosyltransferase V gene in cancer cells: essential role of transcription factor Sp1. J. Biol. Chem., 279, 39574-39583 (2004).

14) Suske G. The Sp1-family of transcription factors. Gene, 238, $291-$ 300 (1999)

15) Beishline K, Azizkhan-Clifford J. Spl and the 'hallmarks of cancer' FEBS J., 282, 224-258 (2015).

16) Shirane K, Kuji R, Tareyanagi C, Sato T, Kobayashi Y, Furukawa S, Murata T, Kubota S, Ishikawa Y, Segawa K, Furukawa K. Gene expression levels of $\beta 4$-galactosyltransferase 5 correlate with the tumorigenic potentials of B16-F10 mouse melanoma cells. Glycobiology, 24, 532-541 (2014).

17) Tagawa M, Shirane K, Yu L, Sato T, Furukawa S, Mizuguchi H, Kuji R, Kawamura K, Takahashi N, Kato K, Hayakawa $\mathrm{S}$, Sawada S, Furukawa K. Enhanced expression of the $\beta 4$ galactosyltransferase 2 gene impairs mammalian tumor growth. Cancer Gene Ther., 21, 219-227 (2014).

18) Chen Y, Wang X, Li W, Zhang H, Zhao C, Li Y, Wang Z, Chen C. $\mathrm{Sp} 1$ upregulates survivin expression in adenocarcinoma of lung cell line A549. Anat. Rec. (Hoboken), 294, 774-780 (2011).

19) Kitamura N, Guo S, Sato T, Hiraizumi S, Taka J, Ikekita M, Sawada S, Fujisawa H, Furukawa K. Prognostic significance of reduced expression of $\beta$-N-acetylgalactosaminylated $N$-linked oligosaccharides in human breast cancer. Int. J. Cancer, 105, 533-541 (2003).

20) Sato T, Furukawa K, Greenwalt DE, Kobata A. Most bovine milk fat globule membrane glycoproteins contain asparagine-linked sugar chains with GalNAc $\beta 1 \rightarrow 4$ GlcNAc groups. J. Biochem., 114, 890-900 (1993).

21) Sato T, Takahashi M, Kawado T, Takayama E, Furukawa K. Effect of staurosporine on $N$-glycosylation and cell adhesion to fibronectin of SW480 human colorectal adenocarcinoma cells. Eur. J. Pharm. Sci., 25, 221-227 (2005).

22) Guo H-B, Randolph M, Pierce M. Inhibition of a specific $N$-glycosylation activity results in attenuation of breast carcinoma cell invasiveness-related phenotypes: inhibition of epidermal growth factor-induced dephosphorylation of focal adhesion kinase. J. Biol. Chem., 282, 22150-22162 (2007).

23) Sato T, Furukawa K. Sequential action of Ets-1 and Sp1 in the activation of the human $\beta$-1,4-galactosyltransferase $\mathrm{V}$ gene involved in abnormal glycosylation characteristic of cancer cells. J. Biol. Chem., 282, 27702-27712 (2007).

24) Tadokoro $T$, Yamamoto $K$, Kuwahara I, Fujisawa H, Ikekita M, Taniguchi A, Sato T, Furukawa K. Preferential reduction of the $\alpha$-2-6-sialylation from cell surface $N$-glycans of human diploid fibroblastic cells by in vitro aging. Glycoconj. J., 23, 443-452 (2006).

25) Dikmen ZG, Gellert GC, Jackson S, Gryaznov S, Tressler R, Dogan P, Wright WE, Shay JW. In vivo inhibition of lung cancer by GRN163L: a novel human telomerase inhibitor. Cancer Res., 65, 7866-7873 (2005).

26) Zhang J, Ren H, Yuan P, Lang W, Zhang L, Mao L. Down-regulation of hepatoma-derived growth factor inhibits anchorage-independent growth and invasion of non-small cell lung cancer cells. Cancer Res., 66, 18-23 (2006)

27) Ogata S, Muramatsu T, Kobata A. Fractionation of glycopeptides by affinity column chromatography on concanavalin A-Sepharose. $J$. Biochem., 78, 687-696 (1975).

28) Baenziger JU, Fiete D. Structural determinants of Ricinus communis agglutinin and toxin specificity for oligosaccharides. J. Biol. Chem., 254, 9795-9799 (1979).

29) Cummings RD, Kornfeld S. Characterization of the structural determinants required for the high affinity interaction of asparaginelinked oligosaccharides with immobilized Phaseolus vulgaris leukoagglutinating and erythroagglutinating lectins. J. Biol. Chem., 257, 11230-11234 (1982).

30) Fukuda M. Lysosomal membrane glycoproteins: structure, biosynthesis, and intracellular trafficking. J. Biol. Chem., 266, $21327-$ 21330 (1991).

31) Christofori G, Semb H. The role of the cell-adhesion molecule E-cadherin as a tumor-suppressor gene. Trends Biochem. Sci., 24, 73-76 (1999)

32) Furukawa K, Clausen $\mathrm{H}$, Sato T. UDP-Gal: $\beta$ GlcNAc $\beta 1,4-$ galactosyltransferase, polypeptide $2-6$; xylosylprotein $\beta 1,4-$ galactosyltransferase, polypeptide 7 (galactosyltransferase I) (B4GALT2-7). Handbook of glycosyltransferases and related genes (Taniguchi N, Honke K, Fukuda M, Narimatsu H, Yamaguchi Y, Angata T eds.), Springer, Tokyo, pp. 63-72 (2014).

33) Ray R, Snyder RC, Thomas S, Koller CA, Miller DM. Mithramycin blocks protein binding and function of the SV40 early promoter. $J$. Clin. Invest., 83, 2003-2007 (1989).

34) Blume SW, Snyder RC, Ray R, Thomas S, Koller CA, Miller DM. Mithramycin inhibits SP1 binding and selectively inhibits transcriptional activity of the dihydrofolate reductase gene in vitro and in vivo. J. Clin. Invest., 88, 1613-1621 (1991).

35) van Die I, van Tetering A, Schiphorst WE, Sato T, Furukawa $\mathrm{K}$, van den Eijnden DH. The acceptor specificity of human $\beta 4$ galactosyltransferase $\mathrm{V}$ indicates its potential function in $O$-glycosylation. FEBS Lett., 450, 52-56 (1999).

36) Guo S, Sato T, Shirane K, Furukawa K. Galactosylation of $N$-linked oligosaccharides by human $\beta$-1,4-galactosyltransferase I, II, III, IV, V, and VI expressed in Sf-9 cells. Glycobiology, 11, 813-820 (2001).

37) Pearce OM, Läubli H. Sialic acids in cancer biology and immunity. Glycobiology, 26, 111-128 (2016).

38) Pinho SS, Seruca R, Gärtner F, Yamaguchi Y, Gu J, Taniguchi N, Reis CA. Modulation of E-cadherin function and dysfunction by $N$ glycosylation. Cell. Mol. Life Sci., 68, 1011-1020 (2011).

39) Machado E, White-Gilbertson S, van de Vlekkert D, Janke L, Moshiach S, Campos Y, Finkelstein D, Gomero E, Mosca R, Qiu X, Morton CL, Annunziata I, d'Azzo A. Regulated lysosomal exocytosis mediates cancer progression. Sci. Adv., 1, e1500603 (2015).

40) Heffernan M, Yousefi S, Dennis JW. Molecular characterization of P2B/LAMP-1, a major protein target of a metastasis-associated oligosaccharide structure. Cancer Res., 49, 6077-6084 (1989).

41) Harduin-Lepers A, Shaper JH, Shaper NL. Characterization of two cis-regulatory regions in the murine $\beta$-1,4-galactosyltransferase gene: evidence for a negative regulatory element that controls initiation at the proximal site. J. Biol. Chem., 268, 14348-14359 (1993).

42) Rajput B, Shaper NL, Shaper JH. Transcriptional regulation of murine $\beta$-1,4-galactosyltransferase in somatic cells: analysis of a gene that serves both a housekeeping and a mammary gland-specific function. J. Biol. Chem., 271, 5131-5142 (1996).

43) Zhou J, Wei Y, Liu D, Ge X, Zhou F, Yun X, Jiang J, Gu J. Identification of $\beta 1,4 \mathrm{GalT}$ II as a target gene of p53-mediated HeLa cell apoptosis. J. Biochem., 143, 547-554 (2008)

44) Ko JH, Miyoshi E, Noda K, Ekuni A, Kang R, Ikeda Y, Taniguchi N. Regulation of the GnT-V promoter by transcription factor Ets-1 in various cancer cell lines. J. Biol. Chem., 274, 22941-22948 (1999).

45) Lou Z, O’Reilly S, Liang H, Maher VM, Sleight SD, McCormick JJ. Down-regulation of overexpressed $\mathrm{Sp} 1$ protein in human fibrosarcoma cell lines inhibits tumor formation. Cancer Res., 65, 1007-1017 (2005). 